\title{
The Emergence of Motives in Liminal Hotspots
}

\author{
Morten Nissen \& Kathrine Solgaard Sørensen
}

\section{Abstract}

The concept of 'motivation' commonly constructs as a psychological essence what is really the paradoxical imposition of a required desire. While the resulting impasse blocked theoretical development for around four decades, pragmatic motivational techniques evolved regardless. These could be (probably to no avail) dismissed for not taking account of the deep theoretical problems. This article suggests instead to re-articulate them with the conceptual repertoire of liminal hotspots, which directs attention to the emergent nature of activities and collectives, and thus motives. This is done as part of an ongoing collaboration with counsellors who experiment with different ways of helping young drug users without taking motivation as premise, in the sense of a pre-requisite, for interventions. Data from recorded counselling situations are analyzed and rearticulated, first in terms of the classical motivation-resistance contradiction; then through pragmatic approaches in counseling, i.e. the prevalent cognitive-client-centered form and the 'solution-focused brief therapy' approach - and finally as motives emergent in liminal hotspots.

\section{Keywords}

Motivation, liminality, subjectivity, counselling, drugs, affect

\section{Introduction}

-How many psychologists does it take to change a light bulb?

-Just one, but the bulb has to really want to change!

This joke expresses a classic understanding of client motivation as a premise for 'change' in psychological practice. This remains a dominant approach, not least since increasing efforts are invested in evidence-basing standard procedures and handling accountability: Lack of motivation is still the most convenient explanation for client drop-out. Furthermore, the unspecified word 'change' seems to work well as a neutral term for pre-defined but allegedly freely chosen health behaviors that are so much in current demand. The classic critiques of the concept, for claiming as a psychological essence what is basically the paradoxical imposition of a required desire (e.g. Osterkamp 1976, Rose 1996, Danziger 1997), are still relevant today. So is the implication that a more genuine and expansive, emancipated kind of motivation might arise from true self- 
determination, either as liberal autonomy (Deci and Ryan 1985) or as participation in social change (Osterkamp 1976).

Thus it could be said that Im Westen nichts Neues ${ }^{1}$ - and we could easily take up positions in the trenches that have remained in place for decades. But we are here to report the appearance of new configurations in no-man's land. A range of motivational technologies have appeared and spread, which simply ignore or assume what the subject really wants, and instead address motivation pragmatically as process, in its operational, affective, and linguistic aspects. From the old watchtower overlooking the battlefield, one can trace the outlines of those techniques leading right back to well-rehearsed skirmishes: Motivation is still a matter of power. But if one steps down and ventures out into that scarred and muddled landscape of practices, and digs into its foundations at the right places, one might encounter something that is at once ancient and brandnew: The emergence of motives. That is to say, an alternative process-approach is possible. One that also addresses wanting as planning feeling and enunciating, but in different terms: Formulated as the becoming of activities, collectivities, and subjectivities in liminal spaces and moments, which then, viewed as sites for the becoming of affects, become 'liminal hotspots'.

Our scouting expeditions have been part of a long-term collaboration with a Danish community of social workers who help young drug users ${ }^{2}$. In this community, the critiques of the uses of 'motivation' as a premise have at least been present for the three decades of our participation (Nissen 2012a,b, Vinum and Nissen 2006). The concept was seen as one of the cornerstones of the profession-centered institutional practices which had had so limited success in drug treatment, especially with young clients, and the critique connected with the increasing political challenges to paternalistic welfare services from the 1980s and onwards (Nissen, 2012c). Also, the cultivation of alternatives to using motivation as premise has its own trajectory within this community: Various versions of 'outreach work' have been attempted, 'motivational interviewing' (Miller and Rollnick, 1991) has been widely adopted, and a particular Swedish model of 'motivation-work', according to which the client's rejection of help was reinterpreted as 'latent motivation' expressed in a 'contact-rebus', was very influential, especially in the 1990s (Revstedt, 1995). Aside from such explicit challenges and alternatives to the use of motivation as premise, off-mainstream therapeutic and counselling traditions have been carriers of some of the wider-reaching implications, often including going beyond the clinical framework itself. The references to "narrative, systemic, and solution-focused approaches" - as it is written in some current self-descriptions of the counsellors we collaborate with - do not point to well-defined clinical standards or procedures, but to more general and holistic ways of reflecting and arranging social work with young drug users. More recently, the U-turn and Helsingung counselling facilities, which we will refer to in more detail in this paper, have sought to create what we have come to term User-Driven Standards of Social Work, not least by experimenting with the spaces and premises of encountering users and with technologies of their selfpresentation, including 'aesthetic documentation' such as publishing recorded songs or video narratives (Nissen, 2014, Bank \& Nissen, 2015).

\footnotetext{
${ }^{1}$ The original title of Erich Maria Remarque's classic WW1 novel “All Quiet on the Western Front”

${ }^{2}$ Note that "social worker", in Denmark, is a generic term for professionals in social work; most Danish social workers are 'pedagogues'; most of the social workers mentioned here are academically trained psychologists working in multidisciplinary institutions.
} 
Such practices are complex and many-sided, and can be articulated in various ways (Mol 2008). In the following, we will demonstrate this by first discussing them in terms of the classic confrontation of motivation with resistance; then as representatives of the pragmatic turn in motivation; and finally, we articulate them in ways we believe are more promising. This way of arranging a multiple articulation is an immanent critique. It is meant to honor the complexity of practices while also suggesting the imposition of a standard, an order that moves from relatively shallow and one-sided answers to the original paradox, towards what we suggest is a deeper conceptualization, which is already potentially there in the practices we study ${ }^{3}$.

This final articulation is the one where we use the concept of liminality in the sense we discuss in the present volume. Liminality points to how the paradox inherent to the concept of motivation is played out in, and co-constitutive of, situated practices. The undecided or heterotopian (Foucault, 1986) quality of motivational practices makes for moments when participants seem to be stuck between, yet for the same reasons potentially emancipated from, given standards. Greco and Stenner call this a 'liminal hotspot':

an occasion characterised by the experience of being trapped in the interstitial dimension between different forms of process, and in the situation of ontological indeterminacy that characterises such a dimension.

(Greco \& Stenner, this issue, 6)

The ensuing affective intensity - the hotness of such liminal spots - has to do with stuckness as well as with potentialities: It arises where paralysis and perplexity overlap and interchange with imagination and creativity.

The most important way in which these practices are liminal is as encounters, as thresholds or entries into participating in emergent collectivities. This is itself a classic theme in social or clinical work conceived as client trajectories through institutional arrangements that include 'initiation rites' (Goffman 1961); but it becomes even more precarious here because of the experimental efforts and aspirations of the social workers. The liminality of the encounter is deepened by the heterogeneity of being 'betwixt and between' (broadly or narrowly defined) 'clinical' practices and practices framed by other standards such as those of youth subculture, pedagogy, art, social activism, or indeed, emergent standards yet to be labelled. If we ask Goffman's question about the frame: "What is it that is going on here?" (Goffman 1986; 247), we cannot provide one simple answer, and nor can the participants; it is always ambiguous, changing, and thus both-and as well as neither-nor (Kofoed \& Stenner, this volume). This constant undecidedness coexists with, co-constitutes, and is co-constituted by the ritual character of the practices: The fact that they are performative: at once doing and displaying - and transformative: enacting radical changes that may have lasting effects.

Further, behind it lie what we might call deeper liminalities such as those implied in - and performed as - youth, personal 'change', drug use, historical transitions such as the rise of 'therapeutic culture' (Illouz 2008), and perhaps even modernity as such (Foucault 1986, Szakolczai 2009), not to mention research as part of it (e.g. MacIntyre 1984; Latour 1993, Stengers 1997, 2010). No doubt, this stretching of the concept of liminality could be an

\footnotetext{
${ }^{3}$ Our use of the Hegelian term 'immanent critique' is not meant to suggest a closed teleology; the tendencies it articulates are constructed as pushing toward and co-defining the radical problematizations that we are trying to achieve - and precisely for that reason, they are beyond any definite closure.
} 
overextension, even if it is already a characteristic move in the liminality literature itself, at least since Turner (1995); however, our point is that those 'deeper liminalities' appear as relevantly co-constituting the liminal spaces and moments we are studying - as when for instance the postclinical 'aesthetic documentation' becomes also a move in the struggles over evidence-basing' a way of exploring the new frontiers between public and private self-presentations, and a prototype for social research (Nissen, 2014).

In such 'liminal hotspots', where participants are trapped between and simultaneously emancipated from given standards, we propose that motives may emerge. The general relevance of this study is two-sided. One side is to suggest liminality as a way of understanding the becoming of motives. The other is conversely, to probe, through a reinterpretation of pragmatic approaches to motivation, the usefulness of the governed or staged micro-genesis of motives for understanding liminality and 'liminal hotspots'.

In the following, we first present a sample of a conversation video-recorded at Helsingung, a small facility for young drug users in Elsinore, Denmark. This material is meant to set the stage and serve as a platform from which to unfold the different versions of 'motivation' that we wish to discuss. Since it is not equally prototypical of all the issues we take up, we supplement it with other materials from the same field, thus also gradually contextualizing it toward a thicker description.

\section{The New Girl}

The excerpt is transcribed and translated from a video-recording of a conversation between Halberg, psychologist, and Emily and Carl, young clients aged 14 and 16, in the spring of 2014. At this moment, these two are the only youths in the "day-team" of clients who are under 18 and spend their days at Helsingung, much of the time doing schoolwork.

The sequence is videotaped because Halberg, inspired by narrative therapy and actor-networktheory, is experimenting with what he calls "appreciative ceremonies", alternative ways to perform verbal self-reflection and recognition in a group-session ritual. He has recently presented the method in STOF, the journal for Danish drug counsellors. He writes about the need to find alternatives to dominant stigmatizing forms of knowledge about clients:

Appreciative practice is a kind of counter-practice, which resists and tries to engage in a struggle against some of the very solid and powerful knowledge that rules. (...) A recurrent element in the day-team is group sessions two times a week. The youths have not exactly been enthusiastic about these conversations, but they have shown a willingness to go into it, and we have worked together to find ways to make the group sessions meaningful.

(Halberg, 2013, 67)

One aspect of the appreciative practice is to recognize some youths' experiences as a generalized basis for dealing with other youths. In the following, Halberg tries to engage Emily and Carl in a conversation about how best to welcome a new girl, Jenny, to the day team.

Halberg: But listen to this, we'd like to just spend 5 minutes on this. So, she starts after the winter break, uh... and we would like, you've all tried this with starting here etc. When it's the winter break, Zeki and I are trying to plan a little bit, how we're going to best welcome Jenny when she comes and so on, - 
Emily: Then we'll bake a cake! (Emily interrupts Halberg's speech. Halberg looks at Emily, but keeps on talking the way he started).

Halberg: Uh... Could you just give us some ideas about what it was like when you started, what was really important to you, in terms of being new and starting here, being accepted in a good way. What do you two think we should do to sort of make her feel like one of the crew here?

$$
\text { (...) }
$$

Emily: (Smiling) We could invite her out to have a cigarette!

(Pause)

Halberg: Mm (nods). What else? (Halberg looks at Carl)

Carl: We can talk to her (Carl shakes his head slightly, leans back and rubs his head). Just like normally. Yeah, I don't know (Carl leans forward and seems a bit uneasy while saying this)

Emily: I think we should just pretend like she's not there, she'll probably like that.

Carl: Yes (Carl looks attentively to Halberg)

Emily: Yes

Halberg: (looks puzzled at Emily) Mm-hm

Carl: We could also throw her a big welcoming party with flags all over the house and...

Emily: SURPRISE!

Carl: Yeah!

Emily: WELCOME TO HELSINGUUUNG!

Halberg: Do you think, uh... like, I get a feeling that you find it a bit unserious to talk about it. We feel, I mean we think it's really important because we want to welcome her in the right way, but do you think it's silly that we ask you?

Emily: Yeah yeah

Carl: No, not really, (Carl is rubbing his eyes), I just don't know what would help.

Halberg: Well (Halberg open up his arms and looks straight up in the room), the reason we're asking you is that you've tried this, you're young and you've tried starting here, and everything you can tell us about what's important when starting here we can bring with us when we think about what to do with Jenny.

Emily: But it's just because you don't think that much about it, because normally when someone new starts in your class or whatever, you're just more like, more open and nice, right, instead of just being closed off and acting like you'd normally do!

Halberg: Yes. But, is that what you in a way would want when you start somewhere new, that people are open and nice, like open as, I mean it could be that you said it sort of sarcastically, but...

Emily: No, I'd really want everyone in a new class where I start to just ignore me....

Halberg: Mm...

Emily: Exactly!

Halberg: $\mathrm{Mm}$

Emily: You've got that just right! 
Halberg: Mm, are you being sarcastic with me now?

Emily: I was being serious at first

Halberg: Yeah, yeah. Yes, yes, yes.

\section{First level: Motivation and Resistance}

At first glance, one can recognize this as a disappointingly traditional kind of social or youth work encounter. Even as Halberg tries to develop a new form of practice, using interesting theoretical resources, he seems to be repeating the well-known pattern of trying to motivate young clients to display an appropriate "reflexivity" in the format of talk in a group session - and the young clients appear to be resistant or at least hesitant. Thus, the problem that he described as the occasion to experiment with this ritual seems to repeat itself.

When we discussed this incident with Halberg at some later point, he was himself puzzled by how much he actually seemed to ignore some quite relevant suggestions made by Emily and Carl: The informal entry route par excellence: the cigarette break; the classic welcoming ritual of baking a cake; the manifestly ceremonial event of the big welcome party. Even the suggestion to completely ignore the newcomer can be seen as relevant to understanding her, even if perhaps not as a suitable course of action. Halberg's most likely reason for not accepting those proposals (in hindsight) was that they appeared to him as resistance - as superficial or ironic, as ways of not doing what he suggested.

Perhaps what we might call the disciplinary clinical standard shines through and, despite intentions, shapes Halberg's actions - and then perhaps those of Emily and Carl too. Following this standard, the group session is a fixed time-space slot where clients' thoughts and feelings are verbally and non-verbally displayed, assessed and manipulated; the standard requires clients to participate and thus semi-publicly self-reflect. Since such group sessions stage ritually the clienttherapist-encounter, they are considered key to the clinical intervention of the institutional set-up as a whole. Being motivated for doing this is often seen as an indication for being motivated for engaging in treatment, which in turn is taken as indicating motivation for 'change'. This standard package allows therapy to work as a projection screen that makes clients' utterances and other actions stand out as 'material displayed'. The meaning of anything the clients say or do is interpreted as indexically defined by the therapeutic space, which in itself implies and demands clients' 'openness' and 'reflexivity'. This is how the idea of baking a cake becomes a move of resistance. Counsellors struggle with clients to 'open up' in their own best interest; clients try to resist exposure without directly challenging the professionals; their ways of resisting are then taken as clinical 'material displayed', and so on (Goffman 1986, Carr 2011).

Halberg and his colleagues are very critical of this way of packaging motivation, but they are stuck with some very strong forces behind it. The clinical standard is underpinning and mediating their recognized expertise; and, in terms of more contemporary governance, it provides the most obvious way to reconcile expertise with 'user influence' - since the standard appoints well-defined 'user' positions (cf. Barington, Halberg \& Nissen, in prep.). Ironically, Halberg's experiment is itself part of what keeps it together, materialized in the video recording, which is defined by and co-defines the frame of the group conversation. He wants to change the standard frame radically, and so he tries to set a new standard, mediated by the documentation, which again implies the standard frame! He is curious about what may come of it, but first he 
must give it a serious try, and recruit the others to play along and do the same. What then occurs is, in Goffman's term (ibid), two different and opposed 'up-keyings', that is, the adding of metareferential layers: Halberg's proposed 'therapy talk game' is countered by clients' ironic or playful moves ${ }^{4}$. Halberg tries to overcome the 'resistance' by yet another up-keying, addressing the irony itself. This turns the clients' moves into material displayed for treatment, thus repeating the clinical standard - but in vain. They all seem to be stuck in the motivation-resistance game imposed by the clinical standard.

How to escape? Perhaps psychology holds a key. One psychological approach that would match this standard asks how the activity addresses the needs of the clients, as those needs are developing and formed as motives. In the drug treatment field, young clients are typically deemed less motivated, partly because they have not yet experienced 'hitting bottom', , and partly because their cognitive capacities for self-reflection have yet to mature (Dennis et.al., 2002). Behind the lack of motivation for counselling, it may be possible to address even deeper developmental needs formed as motives for being with peers and for being recognized by sympathetic adults. Knowing such needs, motivation can be solicited extrinsically, for instance in the shape of rewards. But this tends to set up an explicit regime of behavioral reinforcement that itself begs resistance; and so, even deeper needs must be addressed, which might motivate the activity intrinsically. The idea of a general need for self-determination as choice and control (Deci and Ryan 1985) can be supplemented with considerations about how precisely that is what is demanded of adolescents in a late modern society, specifically through forms of self-reflection (e.g. Mørch, 2006). This might provide reasons for motivating young clients to participate in group sessions, if only these are absolutely voluntary and consistently shaped according to their expressed wishes and choices - just as Halberg's therapy standard claims to be.

However, the sequence we have witnessed could be used to question such optimism: Carl and Emily are indeed at Helsingung and participate in the conversation of their own choice, and Halberg does make sure to keep getting feedback from them; yet their resistance persists. This could be taken to indicate that autonomy, conceived as choice and control in given activities, is limited. Classically, this is explained by the 'depths' of the psyche where conflict resides, as in the Freudian Ego/Id structure or, more generally, as the theoretical positing of motivation as the deployment of volition and self-control to manage 'conflicting motives' (Kehr 2004). The handling of ambivalence, such as motivation versus resistance, with volition, is more generally constitutive of any psychotherapy. The 'talking cure' can only make sense because clients' ways of understanding themselves and their problems are part of what must be changed. Clients' resistance is how the therapist encounters the problem (neurosis, automatic thoughts, dependence, etc.) directly. In that sense, psychotherapy is inherently critical and demanding. This is another way of explaining why motivation and volition are required as premise - and why therapy often fails to treat addiction (in clients with 'weak egos' etc.).

But, being a paradigmatic instance of the problem of volition (Valverde 1998), addiction calls into question the whole therapeutic setup. Thus the fragility of liberal autonomy could point to a wider and more contextual understanding of self-determination. In Osterkamp's version of

\footnotetext{
4 This brings to mind Paul Willis' analyses (1977) of working class students' use of ridicule as a half-hearted kind of resistance.

5 'Hitting bottom' is vernacular, in 12 steps fellowships and beyond, for the ultimate crisis and loss at the end of a social deroute which can be taken as a turning point
} 
expanded motivation (1976), the ways in which activities are defined and make sense in the first place is a conflictual societal issue in which the individual participates. The question is not simply whether Carl and Emily experience control and choice in an immediate sense, but the more demanding issue of how their participation promises ways to enhance their agency as participation in collective control and creation - which is basically what they need. The apparent emotional ambivalence does not reveal intra-psychic dynamics, but addresses contradictions in meaning, understood as possibilities for action; and the urge to resist is itself part of the emergence of a motivation expanded to productively address those contradictions. This theory addresses the paradox of motivation in a much more direct and radical way than Deci \& Ryan's more widely adopted self-determination theory - not least by questioning how self-determination itself becomes a demand and thus repeats the paradox at a higher level.

We will return to that radicalism below. But we must first address an alternative kind of radicalism through which Halberg's problems could be articulated. This proceeds, not as a radical expansion of the concept of needs to encompass resistance, but as a complete rejection of it as relevant at all to the issue of motivation or that of 'change'.

\section{Second level: Escape Attempts}

If therapy works by eliciting a resistance that is assumed as foundational, to the point of paralysis, then it seems obvious to ask: What if it proves more efficient to simply assume motivation at every point (to modify Harvey Sacks' ethnomethodological motto), as a general frame, and influence choices and actions at an operational or affective level? This question characterizes the mainstream approach to motivation and change, which has gained influence in the decades after Osterkamp and Deci \& Ryan. As the notion of "efficiency" reveals, this approach is generally pragmatic and anti-metaphysical. In most versions, this spells positivism in one form or another. But it is not limited to positivism. We shall discuss also the "solutionfocused brief therapy" developed by Steve de Shazer, Inzoo Kim Berg, and their colleagues, which is mostly based on Wittgenstein's critique of psychology. Here, resistance is declared a myth, since this idea of a 'psychic' essence and its symptomal appearances in the clients' utterances is a metaphysical phantom based on a misconception of our language.

To varying degrees these approaches are important as references in our community of social workers. Common to them is what Nikolas Rose termed a "flattening of psychological space" (Rose 2001): Motivation is 'de-paradoxified' (Greco \& Stenner, this volume) by reducing it to a shallow pragmatics. The inner essences consisting of needs, motives, resistance and volitions are ignored, and replaced by technologies of surfaces and immediate encounters ${ }^{6}$.

Let us begin at the simple end of the range.

\section{A. The Self-Calculating Subject}

In our example, one simple mechanism that Halberg uses deliberately is having Emily and Carl talk about how it feels to be new, in order to make them aware of how far they have come since they began at Helsingung. This is even more apparent when 'appreciative feedback', written on

\footnotetext{
${ }^{6}$ The kind of pragmatics that Rose discusses is of course very relevant in other areas of the drug treatment field: The civic responsibility for (pharmacologically) managing brain process. See, to this, e.g. Houborg, 2012, or Nissen, 2012c
} 
post-its by the professionals, is read aloud in these sessions. A few minutes after the sequence above, Halberg takes a sheet with post-its and looks at it:

Halberg: Ah, yes!! This one is about, you know, you have managed to begin your internship, and I just think that's cool! (Looks at Carl, shaking head and smiling), you know, right from when you, like, the first meeting we had down here, almost, we talked about that thing with you wanting to do an internship, and that was your target. And now you're doing it!

This is assumed to be motivating, because, in Albert Bandura's term, it helps developing Carl's self-efficacy (Bandura and Schunk 1981). Halberg's own articulation of it would be more in terms of 'expanding a preferred narrative', but here as on many other occasions the much simpler cognitive articulation is quite sufficient, and it is ubiquitous in the field and far beyond it. It's extremely banal: You're more inclined to do something if you have reason to believe that you can actually do it; and that reasoning can be performed by adding up all the small steps you have already taken in this direction. Rational self-calculation is staged and performed, and more generally, as articulated by Bandura, assumed.

In counselling and social work, this assumption of a self-calculating subject is followed up by an ongoing concern with controlling the pace of progress; as one counsellor explained in an interview:

Dirch: The point is, I'm not in a hurry - that is, I try not to be, I try to move at his pace, and all the time adapt. If he starts to defend himself, and says: "But I can't just - all my friends smoke, too!", then "Oh, I can see that... How is it, really, with your friends?" Always move at his pace, adapt to his feedback. 'Cause you keep getting feedback on where he is at in the conversation. If I move ahead of him, ooh, then they often withdraw, like, "Arrgh, you don't know how it feels", you know? So, all the time, it's like on-off, and find out, when can I push him a bit toward thinking something new, like.

Here, the self-calculating subject comes alive through the counsellor's continuous adaptation of descriptive questions and target-settings. In Dirch's account, we clearly see the inspiration from Motivational Interviewing (cf. Miller and Rollnick, 1991). In this methodology, the client describes her reasons for and against 'change' and sets her own targets accordingly, and the counsellor mirrors those considerations, always following the client, always pretending neutrality.

The pragmatics of this approach lie in simply not addressing the issue of motivation as overall premise and quality. The conversation is premised on the linear scale of 'change', and adverse reasons translate to downscaling targets. This way, the motivation-resistance contradiction is avoided, and what was before interpreted as 'resistance' is now regarded as the client collaborating by "giving feedback" on "where he is". Motivation as package is avoided by simply being assumed, and the brilliant point is: even when the counsellor works with a client who is not yet contemplating 'change, ${ }^{7}$. In this way, the approach never engages with the contents or the desirability of this 'change'. Having read Revstedt's above-mentioned (1995) book on 'motivation-work', Dirch may have 'humanistic' ideas about what clients 'essentially'

\footnotetext{
${ }^{7}$ Originally, MI was based on the "trans-theoretical model" proposed by Prochaska and DiClemente (1986). In this, the process of 'change' is formalized into a sequence of 'stages' that includes the recognition of "contemplation" and even "pre-contemplation" stages as premises of rational deliberation. More recent presentations of MI distance themselves from the idea of such diagnostic metaphysics.
} 
need; but in the counselling space, the technology is one of tuning encounters to the client's immediate preferences, rather than to any 'needs' assumed to lie behind them.

Of course, as we shall see below, that does not in and of itself rule out the articulation of generalizing motives in a more demanding way that recognizes the contentious nature of change as social, and thus reinterpreting the whole problematic of pace and self-calculation within a framework of collectives emerging in liminal spaces.

As always, the figure of the self-calculating subject carries a shadow of the irrational. This dichotomy is foundational to the psy sciences. In the field of motivation, it is currently expressed in the way that pragmatic techniques for accomplishing 'change' split up between assuming motivation and bypassing it completely by nudging: directly influencing what is conceived in 'behavioral economics' as

... an automatic, affective system that requires little or no cognitive engagement, being driven by immediate feelings and triggered by our environments.

(Marteau, Ogilvie et al. 2011, 263)

This reappearance of the classic dichotomy is interesting, not least since it can work as a caricature analogy to some of the ways in which 'affect' and 'materiality' are introduced in social theory as an alleged counterweight or alternative to a rationalism attributed to discourse analysis. In fact, when we articulate some of the experiments with spaces and encounters at Helsingung as modulating affectivity (Bank \& Nissen, 2016), it is worth reflecting whether we get caught in this dichotomy ourselves. But it takes us too far from our present argument to unfold this here.

\section{B. Escape by Declaration}

Instead, we will address another pragmatic way of avoiding the motivation-resistance problem by assuming motivation: Solution-Focused Brief Therapy (SFBT). SFBT has a strong influence on 'our' professionals, as it provides a sophisticated account of counselling that directly rejects the notion of resistance and argues for assuming motivation.

Steve de Shazer, founding father and main figure of SFBT, asserts that 'resistance' is either a way of protecting oneself, e.g. of wanting to slow down, or a therapist error meaning that the intervention does not fit the client's situation (De Shazer \& Dolan, 2014; 4). On this assumption, the surface becomes the foundation:

How the client depicts his situation or constructs reality and what actually happens in the session are accepted by the therapist at face value and adapted to and utilized by the therapist as the foundation of therapy. (de Shazer, 1991, 59).

This recognition of clients as unconditional collaborators is an 'appreciation': a ritual staging and performative expression of the assumption of compliance. As in the widely adapted 'appreciative inquiry' (Cooperrider and Srivastva 1987), appreciation works by constructing a socially sanctioned representation of the client as morally acceptable and identifiable, in practice (as we saw Halberg perform above) as well as in representations of it (as we saw here, and in Dirch's statement).

SFBT is a standard counseling model and tradition. But, unlike most such traditions, SFBT is explicitly opposed to psychology as the attempt to hypothesize and explain psychic essences. The seeming paradox of taking what clients say at face value as a "foundation" is unfolded in an 
extensive reading of, first of all, Wittgenstein's critique of psychology. Steve de Shazer's last book is filled with Wittgenstein quotes to make the point that our tendencies to hypothesize psychic essences (such as motivation or resistance) are misunderstandings of how language works; that references to feelings, beliefs etc. are not meant as 'propositions' about things that exist (perhaps hidden), but more akin to moves in a game. Wittgenstein's suggestion to solve philosophical problems "through an insight into the workings of our language" (Wittgenstein, 2010, \#109, p. 52) is taken directly as a way to solve clinical problems:

Of course, eliminating anything hypothetical and all explanation means that therapists must work hard to simply stay on the surface of the conversation. All that is left is the conversation itself listening and talking - and the description of the conversation looking into the workings of our language. (de Shazer \& Dolan, 2014, 106)

So, SFBT does not at all intervene in psychic essences similar to pain and disease, but simply in conversations. "Looking into the workings of our language" supplies the know-how that allows the counsellor to help accomplish the "practical results" that clients are claimed to be seeking: "To get rid of the problem, plain and simple" (de Shazer, 1991, 110). Writing "problem" in strikethrough signifies that it only exists as deconstructed in the conversation and as replaced with a 'solution'. This also cancels the question of how we know that the problem is being solved, except as the client's pure presence and as her utterances: Client retention and - typically quantified - feedback are the key values.

In another conversation, Halberg has Emily fill in the 'Outcome Rating Scale' (Miller, Duncan et al. 2003) - a formalized client feedback technology - and takes up the problem that the graph representing how she thinks she is doing is declining; this is worrying since statistics have shown this to correlate with likely drop-out. Halberg tries to engage Emily in a quantitative assessment, first of the likelihood that she'll do better, and then of her motivation for it:

Halberg How much do you believe in it? What are the chances the curve will break at some point?

Emily I really don't know

Halberg Do you know how much - you'd be willing to try to make it - if 10 is you'll do anything to make it change, and 0 is you won't lift a finger?

Emily Of course I want to help, I just don't know what would help me

(...)

Halberg I could ask other people, but if I ask you, how worried should I be that it suddenly turns this way (points down)?

Emily Well, there's a chance it suddenly goes WAY down, like, if I forget to take my medication, or something like that, right?, and of course, that's not SMART, is it, because, eh, then I could get HOSPITALIZED

Halberg You wouldn't want that

Emily I wouldn't, but this could, AS SUCH, be necessary IF things really go badly. (Nods). "For the sake of your OWN health"!

Notably, and consistent with SFBT, this quantification is not used out of a belief in psychic entities that can be counted or measured. Quite the opposite, it is a pragmatic way of establishing a workable common sense language in the absence of any metaphysical reference. Numbers both 
objectify and neutralize, deflecting any possible conflict of meaning or implication (Porter 1995) - even when they do not reference anything at all (Nissen \& Barington, 2015).

What emerges is a formalized standard for the meta-level self-governance of motivating one-self as a play of signs: The idea of self-motivating might appear to be engaging in a purely formal and pointless infinite regress (am I motivated for motivating myself? etc.); but this up-keying makes a difference: It shifts the register to a ritual exchange, a self-contained practice of exchanging signs. In this excerpt, the quantified self-assessment of motivation is quite obvious; but, more generally, producing descriptions of 'solution' and assessing 'outcome' with a strong emphasis on the positive is to declare motivation. According to Wittgenstein, that is what prompting a proposition about motivation as an 'inner state' really amounts to, since it does not make sense to want to want (2010, \# 611 ff.). Knowing "the workings of our language", we can appreciate why Emily hears Halberg's question as "do you really want it?" In ordinary language, meta-motivation seems to collapse into motivation, since 'wanting' is not really an action or an object.

In other words, while the other pragmatic approach assumes motivation in order to facilitate it indirectly (by the subject's adding of small steps), this linguistic pragmatics co-creates motivation quite explicitly, but as a move in a language game:

Dirch: My favorite Wittgenstein quote is the one that says: "I only know what I mean when I hear what I say" - which to me shows very well how motivation emerges and is co-created in conversation.

Just so:"in conversation": SFBT is the ritual staging of the assumption of motivation as a verbal exchange of appreciations for promises. This brings to mind Valverde's description (1998) of certain kinds of alcohol treatment in the early 20th century as a "gymnastics of the will", where, like in the gymnastics of the time, display was as important as exercise. With SFBT, the will, which had been buried in the psychology of motivation as volition or self-regulation, comes to the social surface of ritual display in the shape of promises. However, the excerpt reveals how the clinical standard is maintained in SFBT as the unnoticed frame for the manipulation of language - and with it, the resistance and the struggle over which kinds of up-keying should prevail: Halberg's therapy versus Emily's irony. This standard frame is also what Carl and Emily, in the first extract, are struggling with: It molds a common sense that disregards their real predicament, and puts them in a liminal hotspot, stuck between performing a facile positivity and a groundless resistance.

However, again there is more than one way to articulate this; Halberg, Dirch and the other counsellors are struggling, too, as we shall see, and although Emily does not comply in displaying motivation, her irony can be seen as a creative way to reconfigure the liminal hotspot in which she and Halberg are stuck.

\section{Third level: Liminal reconfigurations}

We suggest that both approaches in the previous section can be said to describe the 'pragmatic turn' in motivation. Staging rational deliberation and measuring its effects may appear more pragmatic than staging ritual declarations, but, as we saw, SFBT reconceptualizes such declarations in a pure linguistic pragmatics. Some of the arguments for the 'evidence of effect' of motivational interviewing are phrased as just the kind of cause-effect hypotheses that 
Wittgenstein (and de Shazer et.al.) criticize, but, in a sufficiently nominalist interpretation, difference between the pragmatics of behavioral science and that of an application of Wittgenstein, which claims plain and simple practical results, wanes.

As mentioned, we could side with the resistance that we have seen Carl and Emily perform in our examples, and reveal the pragmatic turn in motivation to be a sham; in the end, it all comes down to a question of power, to the imposition of a standard and to the struggles to fight it off or escape it. The whole pragmatic turn can be likened to the rise of customization in the development of governance by standards (Busch 2011): For example, the ever so individualized combination of (micro-standard) applications and settings still does not challenge the overall frame of the smart-phone brand as a take-it-or-leave it premise, which is structured and legitimized by the customer-user having bought the commodity on the market. Without denying this, however, we want to suggest, as mentioned, that it may be more fruitful to attempt an 'immanent critique' that takes up these tendencies as contradictory, and potentially more inventive than that. Figuratively, we propose to deepen and substantiate the shallow process approaches of the pragmatic turn in motivation, as part of the alternative articulations of the practices and utterances of our social worker collaborators that we have announced at several points in the above.

The task remaining for us in this text, then, is to suggest these alternative articulations. As mentioned, our overall approach will be through the concept of liminality. Our hypothesis is that motives can be seen to emerge in a stronger sense than only as declared in standard conversations - in fact, their intensity rather derives from their emergence as aspects of the becoming of activities, collectives, and subjectivities, in, and out of, the liminal hotspots in which our participants find themselves trapped.

\section{Embryos of Activities and Collectives}

Let us revisit our first scene, the conversation about the new girl. Moves that we at first interpreted as either compliance or resistance can be seen as the first beginnings, the embryos, of new activities:

Carl: We could also throw her a big welcoming party with flags all over the house and...

Emily: SURPRISE!

Carl: Yeah!

\section{Emily: WELCOME TO HELSINGUUUNG!}

Imagine Halberg, at this point, answering "Yes, why don't we do that!"

The affective intensity could be interpreted as connected with their daring moves to ridicule Halberg in his attempts, as the release of emotional energies attached to resistance, in their inner volitional conflict. But it might also be taken as the excitement of a breakthrough. Given another, entirely possible, sequence of events after this scene, this could be the very first moments of what would later be renowned and described by researchers as the grand welcoming party for Jenny. All it would take, at least in the first instance, would be Halberg's affirmation - followed, of course, by the practical organizing, decorating with flags, baking cakes etc.

This way of accepting clients' utterances at face value is quite different from that described by de Shazer, in that the language game of suggestions is actually taken as prompting possible lines of action, beyond the standard conversation, and even beyond the experimental extension of it that 
allows us to see it: Halberg's recorded attempts at "appreciative ceremonies". Of course, the planning and calculation, the pacing of progress and the attunement of dialogue, which we could imagine taking place in preparation for the party, would not seem to address the 'change', the plain and simple point of their being in that counselling facility at all. The common sense question arises: What's it got to do with taking drugs? But this question is ironic, if we recall the emptiness of the term 'change' and the purported therapeutic relevance of the theme of 'welcoming': 'Change', even within the standard of therapy, is generalized far beyond cure, especially when clients are seen as 'young'. This generalization contributes to the liminality, which is sought managed with the imposition of that standard. But rather than imposing that frame, the issue of welcoming, as generalized experience, could easily be worked with as embedded in the activity itself; the party would be constructed practically as a prototypical welcoming.

Welcoming is in fact, if it is allowed to unfold its potential, a ritualized liminal moment, potentially a moment of "meeting youth in movement and on neutral ground": This is a motto that we recorded in earlier dialogues with social youth workers, partly from the same general community (see Nissen 2012a, 2015). In our more recent research dialogues, it connects with attempts at Helsingung to develop encounters by constructing material spaces as spaces of hope, as public spaces and spaces of production (Bank \& Nissen, 2015). Again the multiple readings: 'Designing a welcome' could be the form of a sequence in a therapeutic conversation about it; or it could be a matter of tailoring the entry into a pre-given institutional trajectory to the pace of the person who is welcomed ${ }^{8}$. But it might also constitute steps towards a dialogic construction of activities and collectives. In this way, Dirch's concerns with keeping pace with his clients in the counselling conversations should be understood not as the manipulation of the client's linear progress, but as a concern with ways of constituting community; or, in the words of Greco \& Stenner (this volume), a concern with recognition, not as a mere appreciative utterance, but as the re-attunement of a psycho-social unity of individual and collective identity which has become 'de-coupled' and thus 'problematic' in the liminal situation.

The question and the challenge, then, would be to trace how far this concern reaches, especially whether or not it remains within the common sense confines of therapy. In our case with the party, at least in principle, all participants would have to be open to revising what they do and who they are - for instance, whom do they invite (Jenny only, or her boyfriend, her friends, her parents $?^{9}$ ), how do they present themselves (as a drug facility, an experiment, a school? ${ }^{10}$ ), and, in general, what kind of social youth work agency would be relevant for young people of Jenny's kind, in Jenny's networks etc.; all of this would not only be answered, but also asked in collaboration. This way, the exchange of appreciation for promises could develop into a fuller recognition and engagement, obliging participants to the self of the collective emerging.

Of course, one might wonder whether all this is over-optimistic. If Halberg had seen these potentialities to be present in Carl's and Emily's enthusiasm, would he not be proven the fool if their reaction turned out to have been sarcastic? At the end of the excerpt, we are left in doubt about just that. Does Emily confirm that Halberg was silly to ask them? Was the suggestion to

\footnotetext{
${ }^{8}$ Or it could be a technical modulation of 'affect', a kind of 'nudging'.

${ }^{9}$ Experimenting with outreach through mobilizing young users, and with engaging friends and parents, are already parts of this field of practices.

${ }^{10}$ A "school" was how some young users chose to present Helsingung when they made a film called Modlys [Backlit]. See (February, 2016) https://www.youtube.com/watch?v=uznxmIHvc5s
} 
ignore Jenny serious? Has Halberg got it just right - or is he right that Emily was sarcastic when she said he had? He ends with as much as five confirmations, but when we discussed it with him later, he still wasn't sure how to interpret it.

Our suggestion is that this doubt is itself relevant as a way of taking up the paradox of motivation in a liminal hotspot. Emily and Carl were probably sincere and ironic at once. Resistance, as well as embryonic activities and collectives, were present in the youths' actions, just as both standard therapy and a 'critical trans-pedagogy' (cf. Nissen, 2012a) were present as potentials in Halberg's. These were present, however, not simply, as two lines of action that would each be consistent; in fact, the paradox resides in the ways that the two presuppose, contradict and coconstitute each other (in the space of just four conversational turns). Thus, for instance, the grand welcoming party would make sense partly as a way of resisting therapy, and a welcoming liminal moment for Jenny because she could at once be celebrated and escape the 'hot seat' of attention. On the other hand, the options of standard therapy as well as resistant irony might be seen as fueled to some extent by utopian prospects of emergent community that neither would follow through to realize.

\section{The Openness of Motives as Emergent}

The qualitative differentiation of motives, rather than the quantification and linear dimensionality implied in motivation, is made relevant and possible by the liminal hotspots, in which it is not pre-given which standards or frames should apply. This is a decisive shift of perspective. While 'motivation' turns its back on the world and looks into the inner drives of the psyche, 'motive' retains subjectivity as engaged in the world.

The motives emergent from the sequence could grow and consolidate in many ways and directions, from committing more fully to the Helsingung activities, to aesthetic pursuits, to consolidating an interest in baking, to moving toward social work training, etc. etc. This way of describing motives as emergent invites the understanding of them as acquired socio-cultural forms, as developed in the Vygotskian tradition (e.g. Hedegaard, Edwards et al. 2011); but, just as in the general conceptualization of liminality, it is crucial here to overcome the functionalistic implication that we know in advance the motives that must emerge; motives as emergent are not fully formed and cannot simply be grasped in advance or stipulated as goals. Consequently we should think of our analyses, neither as descriptive nor as prescriptive, but as just-in-time (Jensen 1999): We do not recount the inadvertent reproduction of cultural forms, nor do we stipulate the correct and healthy forms of life based on abstract principles; rather, we ourselves take part in the contentious processes of emergence that we study, and the relevance of our studies derives from this innovative, and therefore risky, ambition (Stengers 1997, 2005). Thus, the concept of liminality promises a participatory approach to micro-genesis, which not only considers and witnesses motives as emergent, but also captures and takes part in the affective excitement of such novelty in motion.

But this requires some qualification.

First, the openness to a range of possible motives would not hold up if it were simply a matter of a flexible planning of the situated activities that lead to the pre-given goal. Rather, the crucial question is whether and how the welcome party prototype could contribute to challenging the constellations of forces that otherwise structure the linear scale of 'change' and its institutional embodiments (as drug treatment etc.). One obvious issue here is stigma and the implied understanding of addiction as an individual propensity; in our dialogues with Halberg and the 
other social workers, we have often discussed whether and how the events, texts, videos, and songs they create together with their young users actually do take up the contentious social issue of addiction - its 'deeper liminalities'. This represents a way of using Osterkamp's abovementioned radical expansion of motivation as emerging in a participation, which reflects and overcomes the social oppression that otherwise individualizes it as the paradoxical imposition of self-control (Osterkamp, 1976).

Some general socio-cultural aspects of the field are classics that remain pertinent (e.g. stigma and social marginalization), but others are currently moving (e.g. relations between users and professionals, or the public-private division). This makes it feasible to stage those aspects in moments and spaces that come to work as both herald and embryo of potentialities for challenging prevailing conceptions. One example is when a young user presents himself in a website video as a sensitive and sensible young man whose cultural interests and anxieties we can identify with, yet at the same time precisely as the ritually liminal boundary figure of a client in treatment ${ }^{11}$.

As another example, we could take up Emily's ironic continuation of Halberg's worries in the second excerpt above (p. xx). At first sight, Emily's performance here appears to be exclusively one of resistance; it does not leave us in doubt as did the sarcasm that she and Carl expressed in the first excerpt. But, at closer inspection, her little show is semantically open as a creative rendering of the alienation inherent to the motivation that Halberg tries to make her declare. Trapped in the liminal hotspot imposed by the SFBT standard that paradoxically opens counselling to arbitrary declarations while reducing it to common sense and its narrow linear conception of development, she performs not only resistance, but a positive recreation of the situation: Taking over and mocking the voice of the worried adult, she reveals the authoritarian and threatening undertones that fly in the face of Halberg's own intentions. We could imagine Emily's utterance as the beginning of a productive - and motivated - practice: The theatrical rendering of her 'duties as client', a Brecht'ian Verfremdung that highlights the paradoxes in common sense notions of treatment. This way, she helps us see how declaring motivation can be rearticulated and developed as a reflective production of artifacts with which we can gain a critical stance.

This version of 'meta-motivation' does not collapse into 'motivation' on account of not really referring to any object, as in the 'ordinary language' described by Wittgenstein and covertly worked on by SFBT. It does in fact refer to an object: It even visibly creates one. Mediated by the productivity of signs (to which de Shazer should have perhaps paid more attention in Derrida, whom he often references), we can indeed want to want, as the Vygotskians have long explored (cf. Sannino 2015). This is in fact merely to stress another aspect of what Halberg and his colleagues are already doing, not just with 'aesthetic documentation' (videos etc.), but also with Halberg's experiments with the artifact-mediation of 'appreciation practices' (using post-its etc.).

Second, and finally, the Vygotskian idea of acquisition implies that the potential motive is in some sense already present before its acquisition. Just as the motive, in itself, directs toward a goal that is in the future-as-present. As this seems to lean toward a functionalist view of development, and a rationalist view of action, it is tempting to suggest instead that motives are simply affects that are simultaneous with activities and collectives. In the moment of becoming, then, any affectivity would be reserved for a pure negativity, an openness as such. This approach

${ }^{11}$ See, e.g. (February, 2016) https://vimeo.com/111205979 
would read Carl's and Emily's ambivalent enthusiasm as purely negative, not exclusively as moves of resistance, but as coming from their not doing what Halberg suggests. Yet, this misses important aspects of the complex temporality of motivation. We are here inspired by Wetherell's reconstruction of affect in terms of practice, and, in particular, in terms of those moments of practices where specific forms and semantic patterns are emergent but not yet settled (Wetherell 2012). The kinds of affectivity that we encountered in Carl's and Emily's enthusiasm are not psychic essences to be manipulated, but neither are they just expressions of the absence of, or emancipation from, structure (cf. Stenner and Moreno-Gabriel, 2013). Rather, they are aspects of emergent psycho-social collectives, as engagements and concerns with that which is anticipated, and even not-yet-known (Bloch 1995) - yet which are, as such, importantly present.

The strongest motivational forces, probably, are those that are directed toward utopian horizons that co-define what we are - and the 'we' who are that - more profoundly than the existing or the merely possible. These are the imaginations of our own development which excite the liminal hotspots in which we are stuck with the silver lining of potentiality, since they remain open to Derrida's l'avenir - but regarded as process in the deep sense, that is, without freezing that moment of openness itself in a "contentless declaration of an élan vital in and for itself", which "repeatedly produces nothing but process", as Ernst Bloch $(1995,201)$ says critically of Bergson.

\section{References}

Bandura, A. and D. H. Schunk (1981). "Cultivating competence, self-efficacy, and intrinsic interest through proximal self-motivation." Journal of personality and social psychology 41(3): 586.

Bank, M. \& Nissen, M. (2016). "Beyond Spaces of Counselling." British Journal of Guidance and Counselling.

Bloch, E. (1995). The Principle of Hope. Cambridge, Mass, USA, MIT Pres.

Busch, L. (2011). Standards - Recipes for Reality. Cambridge, Mass, MIT Press.

Carr, E. S. (2011). Scripting Addiction. The Politics of Therapeutic Talk and American Sobriety. Princeton. N.J., USA, Princeton University Press.

Cooperrider, D. L. and S. Srivastva (1987). "Appreciative inquiry in organizational life." Research in organizational change and development 1(1): 129-169

Danziger, K. (1997). Naming The Mind. How Psychology Found its Language. London, Sage.

Deci, E. L. and R. M. Ryan (1985). Intrinsic motivation and self-determination in human behavior, Springer Science \& Business Media.

Dennis, M., Titus, J. C., Diamond, G., Donaldson, J., Godley, S. H., Tims, F. M., ... \& Scott, C. K. (2002). The Cannabis Youth Treatment (CYT) experiment: rationale, study design and analysis plans. Addiction, 97(s1), 16-34.

De Shazer, S. (1991). Putting difference to work. New York, W.W.Norton \& Co. 
De Shazer, S. and Y. Dolan (2012). More than miracles: The state of the art of solution-focused brief therapy, Routledge

Foucault, M. (1986). "Of Other Spaces." Diacritics 16(1): 22-27.

Goffman, E. (1961). Asylums. Essays on the Social Situation of Mental Patients and Other Inmates London, Penguin Press.

Goffman, E. (1986). Frame Analysis. An Essay on the Organization of Experience. Boston, North Eastern University Press.

Halberg, M. (2013). "Skriften på væggen - gruppesamtaler som værdsættende ceremoni." [The Writing on the Wall - Group Conversations as Appreciative Ceremony]. Stof (22): 13.

Hedegaard, M., et al. (2011). Motives in children's development: cultural-historical approaches, Cambridge University Press.

Houborg, E. (2012). "The Political Pharmacology of Methadone and Heroin in Danish Drug Policy ." Contemp. Drug Probs. 39: 38.

Illouz, E. (2008). Saving the Modern Soul. Therapy, Emotions, and the Culture of Self-Help. Berkeley, University of California Press.

Jensen, U. J. (1999). Categories in Activity Theory: Marx' Philosophy Just-in-time. Activity Theory and Social Practice: Cultural-Historical Approaches S. Chaiklin, M. Hedegaard and U. J. Jensen. Aarhus, Aarhus: University Press: 79-99.

Kehr, H. M. (2004). "Integrating implicit motives, explicit motives, and perceived abilities: The compensatory model of work motivation and volition." Academy of management review 29(3): 479-499.

Latour, B. (1993). We have never been modern. Hertfordshire, UK, Harvester Wheatsheaf.

MacIntyre, A. (1984). After Virtue. Notre Dame, Indiana, USA University of Notre Dame Press.

Marteau, T. M., et al. (2011). "Judging nudging: can nudging improve population health?" Bmj 342.

Miller, S. D., et al. (2003). "The outcome rating scale: A preliminary study of the reliability, validity, and feasibility of a brief visual analog measure." Journal of brief Therapy 2(2): 91-100.

Miller, W. R. and S. Rollnick (1991). Motivational interviewing: Preparing people to change addictive behavior. New York, Guilford Press.

Mol, A. (2008). The Logic of Care. Health and the Problem of Patient Choice. New York, Routledge.

Mørch, S. (2006). Learning to become youth. An action theory approach. Outlines. Critical Practice Studies, 8(1), 3-18.

Nissen, M. (2012a). The Subjectivity of Participation. Articulating Social Work Practice with Youth in Copenhagen. London: Palgrave MacMillan. 
Nissen, M. (2012b). "Writing Drug Cultures." Culture \& Psychology 18: 198-218.

Nissen, M. (2012c). "Recognizing life - a study in the atheist micro-biopolitics of drugs." Subjectivity.

Nissen, M. (2014). Could Life Be... Producing Subjectivity in Participation. Collaborative Projects. A. Blunden. London, Brill: 69-84.

Nissen, M. (2015). "Meeting youth in movement and on neutral ground." Dialogic Pedagogy: An International Online Journal 3.

Nissen, M. Barington, K. (2016). Numbers: Manageable Nothingness or User- Driven Standards?

Nothingness. J. W.-L. Bang, D.A., Information Age Publishing.

Osterkamp, U. (1976). Motivationsforschung 1-2 Frankfurt/New York, Campus Verlag.

Philp, M. (1979). "Notes on the form of knowledge in social work." The Sociological Review 27(1): 83112.

Porter, T. (1995). "Trust in numbers." The pursuit of objectivity in science and public life: 50-51.

Revstedt, P. (1995). Ingen er håbløs. Motivationsarbejde i teori og praksis [No-one is Hopeless. Motivation Work in Theory and Practicel. København, Hans Reitzels Forlag.

Rose, N. (1996). Inventing Our Selves. Psychology, Power, and Personhood Cambridge, Cambridge University Press.

Rose, N. (2001). "Normality and Pathology in a Biological Age." Outlines 3(1): 19-34.

Sannino, A. (2015). "The principle of double stimulation: A path to volitional action." Learning, Culture and Social Interaction.

Stengers, I. (1997). Power and invention. Situating science. Minneapolis, USA, University of Minnesota Press.

Stengers, I. (2010). Cosmopolitics I. Minneapolis, University of Minnesota Press.

Stenner, P. and E. Moreno-Gabriel (2013). "Liminality and affectivity: The case of deceased organ donation." Subjectivity 6(3): 229-253.

Szakolczai, A. (2009). "Liminality and Experience: Structuring transitory situations and transformative events." International Political Anthropology 2(1): 141-172.

Turner, V. (1995). The ritual process: Structure and anti-structure, Transaction Publishers.

Valverde, M. (1998). Diseases of the Will. Alcohol and the Dilemmas of Freedom. Cambridge, Cambridge University Press.

Vinum, C. and M. Nissen (2006). "Street Level Society. Social interventions into young people's drug taking in Copenhagen." Critical Social Work 7(2). 
Wetherell, M. (2012). Affect and emotion: A new social science understanding, Sage Publications.

Willis, P. (1977). Learning to labour. How working class kids get working class jobs Aldershot/UK, Gower Press

Wittgenstein, L. (2010). Philosophical investigations, John Wiley \& Sons 